\title{
HLA Class II Antigen Presentation in Prostate Cancer Cells: A Novel Ap- proach to Prostate Tumor Immunotherapy
}

\author{
Bently Patrick Doonan and Azizul Haque*
}

\begin{abstract}
Department of Microbiology and Immunology, Charles Darby Children's Research Institute, and Hollings Cancer Center, Medical University of South Carolina, 173 Ashley Avenue, Charleston, SC 29425, USA
\end{abstract}

\begin{abstract}
Prostate cancer is a deadly disease that is in drastic need of new treatment strategies for late stage and metastatic prostate cancer. Immunotherapy has emerged as a viable option to fill this void. Clinical trials have been conducted that induce tumor clearance through cytotoxic T lymphocyte (CTL) activation, these studies have had mixed outcomes with the overlying problem being the lack of a complete immune response with sustained killing and the formation of tumor specific memory cells. To overcome this, we have outlined the need for activating the HLA class II pathway in inducing a sustained CD8 $+\mathrm{T}$ cell response and the development of effective memory. We have also discussed the ability of prostate cancer cells to express stable HLA class II molecules that can be manipulated for tumor antigen (Ag) processing and presentation. This review also sets to outline new directions that exist for the use of class II-restricted Ags/peptides in devising cancer vaccines as well as combined chemoimmunotherapy. A better understanding of these concepts will improve future cancer vaccine studies and further the field of cancer immunobiology.
\end{abstract}

Keywords: Prostate cancer, HLA class II proteins, Hormones, GILT, Antigen processing and presentation, CD4+ T cells.

\section{INTRODUCTION}

Prostate cancer is the second most commonly diagnosed cancer in men and accounts for a great deal of morbidity and mortality in the male population $[1,2]$. Current strategies to combat the disease include hormone therapy, surgery, radiation, and chemotherapy [1, 3-6]. Though effective at stalling the progression of the disease, these treatments do little to stop later stage metastatic prostate cancer, for which there is no standard of care outside of palliative support [7]. This suggests the need for new therapy techniques to combat the illness, such as the use of cancer vaccines and combined chemoimmunotherapy [8-10]. The concept of immunotherapy is not a relatively new idea; many trials have been conducted involving cancer vaccines aimed at eliciting a cytotoxic T lymphocyte (CTL) response with varying results [9, $11,12]$. These trials represent a great step toward applicable standards of care but they have failed to produce complete tumor clearance, the induction of a complete immune response, and the production of tumor specific memory $\mathrm{T}$ cells. The reason for this being the absence of therapies designed at invoking the HLA class II pathway of immune recognition.

While the importance of the class II pathway has been greatly appreciated $[4,13-16]$, it is poorly understood by most and is often overlooked when developing cancer vaccine strategies. This neglect represents the downfall of most tumor vaccine clinical trials as the cytotoxic response induced by CD8+ T lymphocytes is short-lived and unsustain-

\footnotetext{
*Address Correspondence to this author at the Department of Microbiology and Immunology, Medical University of South Carolina, 173 Ashley Avenue, BSB-201, Charleston, SC 29425, USA; Tel: 843-792-9466, Fax: 843792-2464, E-mail: haque@musc.edu
}

able [17]. Activation of $\mathrm{CD} 4+\mathrm{T}$ cells is required to stimulate and prolong $\mathrm{CD} 8+\mathrm{T}$ cell activity, activate $\mathrm{B}$ cells, and to develop long-lasting tumor-specific memory T cells. CD4+ $\mathrm{T}$ cells also have the ability to directly kill tumor cells, to a much lesser degree than $\mathrm{CD} 8+\mathrm{T}$ cells, through the release of cytotoxic cytokines and immunological stimulatory molecules $[16,18]$. For these reasons, the class II pathway must be utilized for cancer vaccines to have a high clinical value. We and others have focused on developing strategies of using HLA class II inducing cancer vaccines, which will be highlighted in this review [4, 19-23].

Unlike the HLA-class I molecule which is conserved across almost every cell in the body, the class II molecule is mostly absent from somatic cells and in general is present on the surface of professional antigen presenting cells (APC) like B cells, macrophages, and dendritic cells (DC) [24]. Studies have shown that tumor cells express the class II molecule but at much lower levels than APCs, and this may be a factor in cancer cell immune evasion [25]. Our laboratory previously showed that prostate cancer cells express stable class II molecules which could be exploited for cancer vaccine development [4]. Our laboratory has also shown that the expression of class II proteins in prostate cancer cells can be upregulated through manipulation of the tumor growth condition and that the use of class II-restricted tumor Ags shows real promise for novel prostate cancer immunotherapy.

An important aspect of the class II pathway that can be exploited for cancer vaccine formation is the use of class IIrestricted tumor derived antigens (Ags). Many of these Ags have been discovered for a variety of cancers [26-36], and viable prostate cancer tumor Ags do exist. In this review, we will mention some of these tumor Ags and describe their importance in cancer cell recognition by the immune system 
A

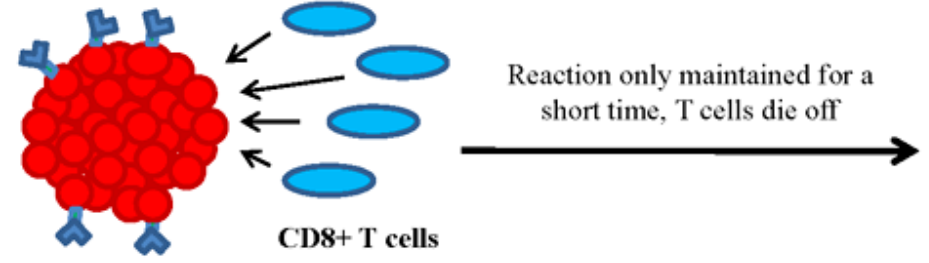

Prostate Tumor Cells

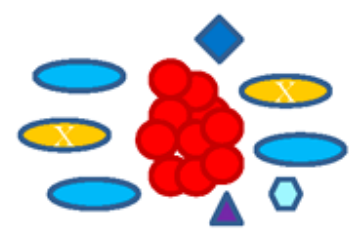

Reduced tumor burden, incomplete clearance

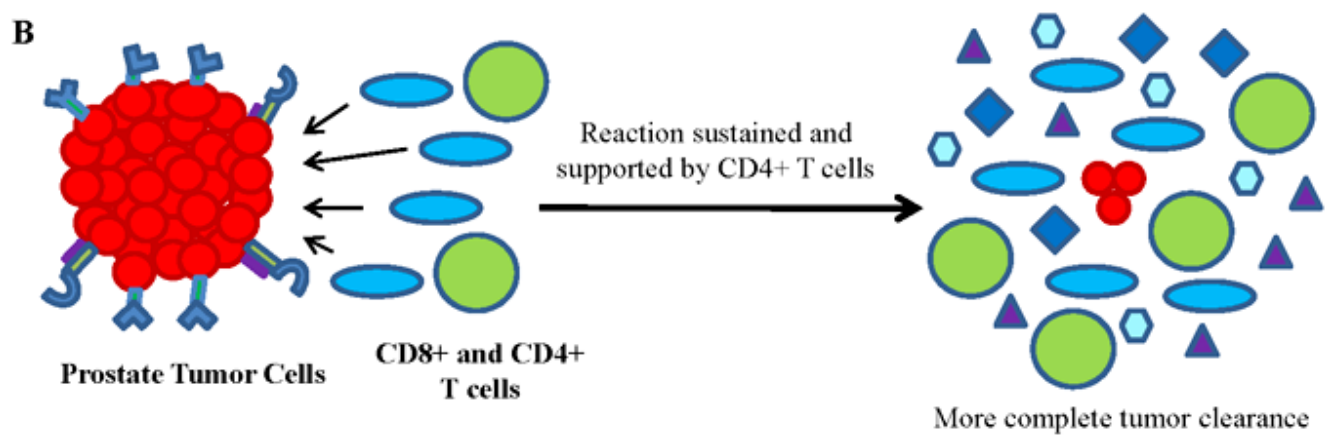

HLA class I HLA class II O $\triangle \triangle$ Cytokines and stimulatory molecules

Fig. (1). Requirement of both CD4+ and CD8+ T cells in the induction of long-lasting immunological memory against prostate cancer cells. (A) CD8+ T cells recognize class I-restricted tumor-derived antigenic peptides and directly kill prostate cancer cells reducing tumor burden. However, this reaction is not sustained for a very long period of time and the remaining tumor mass may continue to divide and progress. (B) Tumor cells that express or that may be induced to express HLA class II molecules can stimulate both CD4+ and CD8+ T cells. When both class I and class II pathways are active, more complete tumor clearance occurs as CD4+ T cells act to prolong the CTL response and aid in effective tumor killing through the release of granules, cytokines and immune stimulatory molecules. Unique to this reaction, tumor specific lasting CD8+ memory T cells are established and will aid in halting future tumor development.

and how this can be exploited for effective immunotherapy when put in conjunction with cancer cell manipulation. This review will also highlight a recent case study that used combined chemoimmunotherapy to overcome hormonerefractory metastatic prostate cancer and the insight that this case gives to the improvement of future cancer vaccine strategies [8]. When taken together, this information proposes a viable guideline for the development of novel techniques for immunotherapy and the furthering of the field of cancer immunobiology.

\section{HLA Class II Pathway for CD4+ T cell Recognition of Prostate Cancer Cells}

The class II pathway is vital in the induction of a prolonged antitumor response $[18,37,38]$. And its importance cannot be overstated. The class II pathway is directly responsible for prolonged activation of CD8+ T cells, direct tumor killing via cytotoxic cytokines and the development of tumor specific memory $\mathrm{T}$ cells. As shown in Fig. (1A), when CD8 $+\mathrm{T}$ cells recognize the HLA class I molecule on the surface of prostate cancer cells, their cytotoxic effect can kill the tumor cells, reducing the overall tumor burden. However, this reaction is not sustained for a very long period, and the T cell begins to die off without the establishment of effective immunological memory. When the same tumor cells can present class II molecules on their surface for CD4+ $\mathrm{T}$ cell recognition in conjunction with the $\mathrm{CD} 8+\mathrm{T}$ cell response, a more complete immune response occurs (Fig. 1B). The acti- vated CD4+ cells $\mathrm{T}$ cells not only stimulate the CD8+ cells and prolong their activity, they also directly release cytokines and immune stimulatory molecules that further reduce the tumor burden. Vital to this interaction is the development of memory $\mathrm{CD} 8+\mathrm{T}$ cells that will remain in circulation and respond to any resurgence of the tumor cells that might occur.

The class II Ag presentation pathway is quite different from the class I pathway in that tumor-derived proteins or Ags are endocytosed and processed by cells that express the class II molecule, resulting in the formation of novel shorter cancer peptides that can activate CD4+ T cells [17]. The HLA class II molecule expressed on the surface of professional APCs and some cancer cells is an alpha $(\alpha)$ /beta $(\beta)$ heterodimer that is produced in the endoplasmic reticulum (ER). Inside of the ER another protein, the invariant chain (Ii), is also synthesized and bound to the class II molecule. This complex then moves from the ER through the transGolgi network to the endosomal and lysosomal compartments [22, 24, 39]. In these compartments, the Ii is removed and a chaperone molecule HLA-DM acts by selectively loading peptides into the class II binding groove [22]. The peptides that are loaded into the complex have been endocytosed by the cells and processed in the endosomal and lysosomal compartments by different cysteinyl and aspartyl cathepsins and reducing agents like Gamma-Interferon-inducible Lysosomal Thiol reductase (GILT), which prostate cancer 
Table 1. Potential Prostate Cancer Ags and Peptides Capable of Inducing CD4+ T Cell Responses via the HLA Class Pathway

\begin{tabular}{|c|c|}
\hline Prostate Cancer Ags & Class II-restricted epitopes \\
\hline $\begin{array}{l}\text { Prostate Specific Antigen } \\
\text { (PSA) }\end{array}$ & $\begin{array}{l}\text { PSA }_{49-63} \\
\text { (ILLGRM }^{1} \text { SLFM }^{1} \text { PEDTG)* }\end{array}$ \\
\hline PSA & $\begin{array}{l}\text { PSA }_{64-78} \\
\text { (QVFQVSHSFPHPL YD) }\end{array}$ \\
\hline $\begin{array}{l}\text { Prostatic Acid Phosphatase } \\
\text { (PAP) }\end{array}$ & $\begin{array}{l}\text { PAP }_{133.152} \\
\text { (NPILLWQPIPVHTVPLSEDQ) }\end{array}$ \\
\hline PAP & $\begin{array}{l}\text { PAP }_{173-192} \\
\text { (KSEEFQKRLHPYKDFIATLG) }\end{array}$ \\
\hline $\begin{array}{l}\text { Prostate Specific Membrane Antigen } \\
\text { (PSMA) }\end{array}$ & $\begin{array}{l}\text { PSMA }_{17} \\
\text { (RPRWLCAGAL VLAGGFFLLGF) }\end{array}$ \\
\hline PSMA & $\begin{array}{l}\text { PSMA }_{100} \\
\text { (WKEFGLDSVELAHYD) }\end{array}$ \\
\hline PSMA & $\begin{array}{l}\text { PSMA }_{206} \\
\text { (GKVFRGNKVKNAQLA) }\end{array}$ \\
\hline PSMA & $\begin{array}{l}\text { PSMA }_{459} \\
\text { (NYTLRVDCTPLMYSL) }\end{array}$ \\
\hline PSMA & $\begin{array}{l}\text { PSMA }_{576} \\
\text { (VAQVRGGMVFELANSIVLPFD) }\end{array}$ \\
\hline PSMA & $\begin{array}{l}\text { PSMA }_{730} \\
\text { (RQIYVAAFTVQAAAE) }\end{array}$ \\
\hline
\end{tabular}

Table 1. Some of the known HLA class II-restricted tumor derived Ags and peptides from prostate Cancer Cells.

*1 indicates that $\mathrm{M}$ is substituted for $\mathrm{H}$.

cells lack [4]. Once the peptide has been properly cut and folded into a functional ligand, it is loaded onto the class II binding groove. The entire complex is then moved to the cell's surface and is presented to CD4+ T cells [20, 40]. Unlike tumor cells, APCs express costimulatory molecules such as CD80 and CD86 that enhance the T cell Receptor (TcR)ligand complex interaction [23]. The presentation of tumorderived epitopes via the class II pathway is also important in terms of cross-presentation and/or bystander presentation by $\mathrm{DC}$ for activation of CD8+ $\mathrm{T}$ cells through $\mathrm{CD} 4+\mathrm{T}$ cell stimulation [25].

\section{HLA Class II-restricted Prostate Cancer Ags and Pep- tides}

In association with the importance of the class II pathway in cancer vaccine studies, the discovery of tumor-associated Ags that can be exploited is of great importance and has been studied thoroughly [26-36, 41]. We have previously outlined the importance of new epitope discovery as it applies to improved strategies for immunotherapy in cancer, autoimmunity, and infectious disease [17]. Many tumorassociated Ags have been discovered in various cancer types, with the majority being restricted to $\mathrm{CD} 8+\mathrm{T}$ cell recognition. Stated earlier in this review, the strides made in CTL inducing cancer vaccines have provided a good foundation for improved prostate cancer therapy. Lacking in these advances is the induction of the class II pathway. One reason for this is the relatively small number of class II-restricted tumor-associated Ags discovered. In order to induce the HLA class II pathway tumor proteins must be unique in structure and sequence in order to bind with the class II binding groove [14, 42]. Also, many times peptides must be processed by professional APCs in order to bind to the class II complex and interact with TcR on CD4+ T cells [42, 43]. There are many Class II-restricted tumor Ags that have been discovered, but prostate cancer remains an area with few viable tumor Ags identified, a short list of which can be found in Table 1 [34, 44, 45].

Table 1 lists a few potential prostate tumor-associated Ags that could be exploited for class II-restricted Ag presentation. Among these are Prostate Specific Antigen (PSA), Prostatic Acid Phosphatase (PAP), and Prostate Specific Membrane Antigen (PMSA) [6]. Each possible tumor associated $\mathrm{Ag}$ has pros and cons to its use and further investigation into each must be performed [44, 45]. PSA was one of the first prostate tumor Ags discovered and has been the focus of many studies as it also has clinical relevance [7]. PSA levels in serum fluctuate with prostate cancer progression and remission so they have been used as an effective marker to test for disease activation. Due to this, PSA has been an attractive target for cancer immunotherapy with mixed results of its effectiveness [7]. If a class II-restricted PSA epitope could be exploited, then its clinical application in cancer vaccines would greatly be increased. In order to identify 
class II-restricted prostate cancer Ags an important term, immunodominance, must first be properly defined to set a guideline for tumor epitope generation. Immunodominance refers to the ability of the immune system to modulate and focus $\mathrm{T}$ cell responses to a select number of epitopes [17]. The immune system does not respond equally to each and every prostate tumor Ag synthesized, and more importantly many epitope sequences of tumor Ags work against the immune system by inducing tolerance and aiding in immune avoidance. By discovering the immunodominant epitope segment of a known prostate tumor Ag like PSA, immune avoidance can be overcome and the efficiency of a tumor vaccine would be greatly improved. Immunodominant peptides are also preferential for tumor vaccines as they generally act as the best ligands at interacting with the TcR of CD4+ T cells [44]. Investigation into exploiting these and other prostate tumor Ags for class II-restricted Ag presentation will advance the clinical benefit of immunotherapy of prostate cancer.

\section{Ag Processing and Presentation in Prostate Cancer Cells}

Ag processing and presentation as performed by professional APCs has been described in this review. What has yet to be mentioned is how prostate cancer cells differ from APCs and how this affects possible cancer vaccine strategies. One important characteristic that prostate cancer cells lack is the presence of GILT in endosomal and lysosomal compartments, altering the Ag processing capability of prostate cancer cells. Without GILT, the activity of cathepsins may decrease and the processing of viable tumor epitopes for class II presentation is decreased [20,46]. Our recent studies have shown that melanoma cells transfected with GILT may upregulate costimulatory molecules like CD80 and CD86, improving class II-ligand complex and TcR interactions (unpublished data). GILT has also been shown to be vital in the reduction of cysteinylated peptides for proper Ag presentation; a quality that when absent, renders cancer cells that express non-reduced peptides muted as they may not activate $\mathrm{T}$ cells [42]. With this in mind, if prostate cancer cells could be modified to express GILT and other costimulatory molecules, then Ag processing and presentation via prostate cancer cells could be restored to near professional APC levels. The question left to answer being, do prostate cancer cells express viable class II molecules on their surface that can be exploited?

For a long time the accepted belief was that cancer cells did not express any class II on their surface as a means for immune avoidance. Recent discoveries by our laboratory and others have shown that some cancer cells do express functional HLA class II molecules on their surface that can be exploited for cancer vaccine strategies [47, 48]. Our laboratory has shown that prostate cancer cells express some components of the class II pathway, and that the expression of stable class II dimers can be induced by manipulating growth conditions, mainly by adding hormones to the culture condition of prostate cancer cells [4]. In the study performed, our laboratory manipulated the culture conditions of various prostate cancer cells and evaluated surface class II expression through Western blot analysis [4]. The results showed that prostate cancer cell lines (PC-3 and CWR22Rv1) expressed detectable levels of $\mathrm{DR} \alpha$ and $\mathrm{DR} \beta$ molecules when cultured in media rich in hormones (progesterone, testosterone, cortisol, corticosterone, triiodothyronine, and thyroxine). More importantly, stable class II DR $\alpha \beta$ dimer expression was shown. This finding raises the possibility that prostate cancer cells could be used as APCs for direct presentation of self Ags for CD4+ T cell stimulation. Prostate cancer cells alone are poor APCs and express very low levels of the class II molecules. When cultured in normal culture media (e.g., RPMI + calf serum or FBS), no detectable upregulation of class II molecules is seen and $\mathrm{Ag}$ presentation capability is minimally changed (Fig. 2). When the prostate cancer cells are incubated in the hormone rich media (e.g., RPMI + cosmic calf serum), class II-transactivator (CIITA) as well as stable $\alpha \beta$ dimer and the Ag presenting capability of the prostate cancer cell is increased. Further improving the Ag processing and presentation of the prostate cancer cells is the upregulation of GILT in the prostate cancer cells, resulting in an increase of accessory molecules that aid in $\mathrm{T}$ cell recognition (Fig. 2). This data is important to note as it implies that through manipulation of the tumor environment hormone levels, and the induction of GILT, prostate cancer cells can express functional class II molecules that are capable of activating CD4+ T cells [4].

Our laboratory is not the only group researching the potential for class II directed cancer vaccines, OstrandRosenberg et al have made great contributions to the study and have discovered some important characteristics of the class II pathway as it relates to cancer vaccine development $[22,23,25]$. Importantly, they claim that the tumor peptides derived by APCs may be immunogenic, but for the most part the patient becomes tolerized to the tumor peptides and no reactive CD4+ $\mathrm{T}$ cells are produced [22]. So, Ag presentation of tumor derived peptides that are synthesized in the absence of Ii represent a unique subset of peptides that may be able to overcome the induced tolerance seen [22]. They also contest that Ii negative class II-expressing cells are significantly better activators of tumor-reactive CD4+ T cells. By creating novel peptides, a diverse repertoire of CD4 + T cells could be activated resulting in a better immune response and an improved prophylactic benefit [22]. This phenomenon may not hold true for every tumor-derived epitope, but it does open up the field of class II vaccine candidates and it also presents a novel mechanism for avoiding $\mathrm{T}$ cell tolerance [49]. We have recently demonstrated that HLADM-negative cells preferentially present self Ag (e.g., collagen II peptide) to stimulate CD4+ T cells [19]. Coupling these two discoveries together, a concept that evolves is the existence of a DM-/Ii- class II pathway in cancer cells and that DM-/Ii- cancer cells are capable of inducing antitumor immune responses and avoiding $\mathrm{T}$ cell tolerance [19, 49]. These findings should be looked at as reference points for future class II-specific cancer vaccine trials.

\section{Future Directions for Improved Cancer Vaccination and Therapy}

Currently, immunotherapy does exist to treat prostate cancer but the results have been mixed [3, 5, 7, 11, 50-52]. The most common mode of therapy being delivery of prostate cancer peptides loaded on DC $[8,53]$. Recent data suggest that more than four hundred prostate cancer patients have been treated with some form of DC loaded cancer vac- 


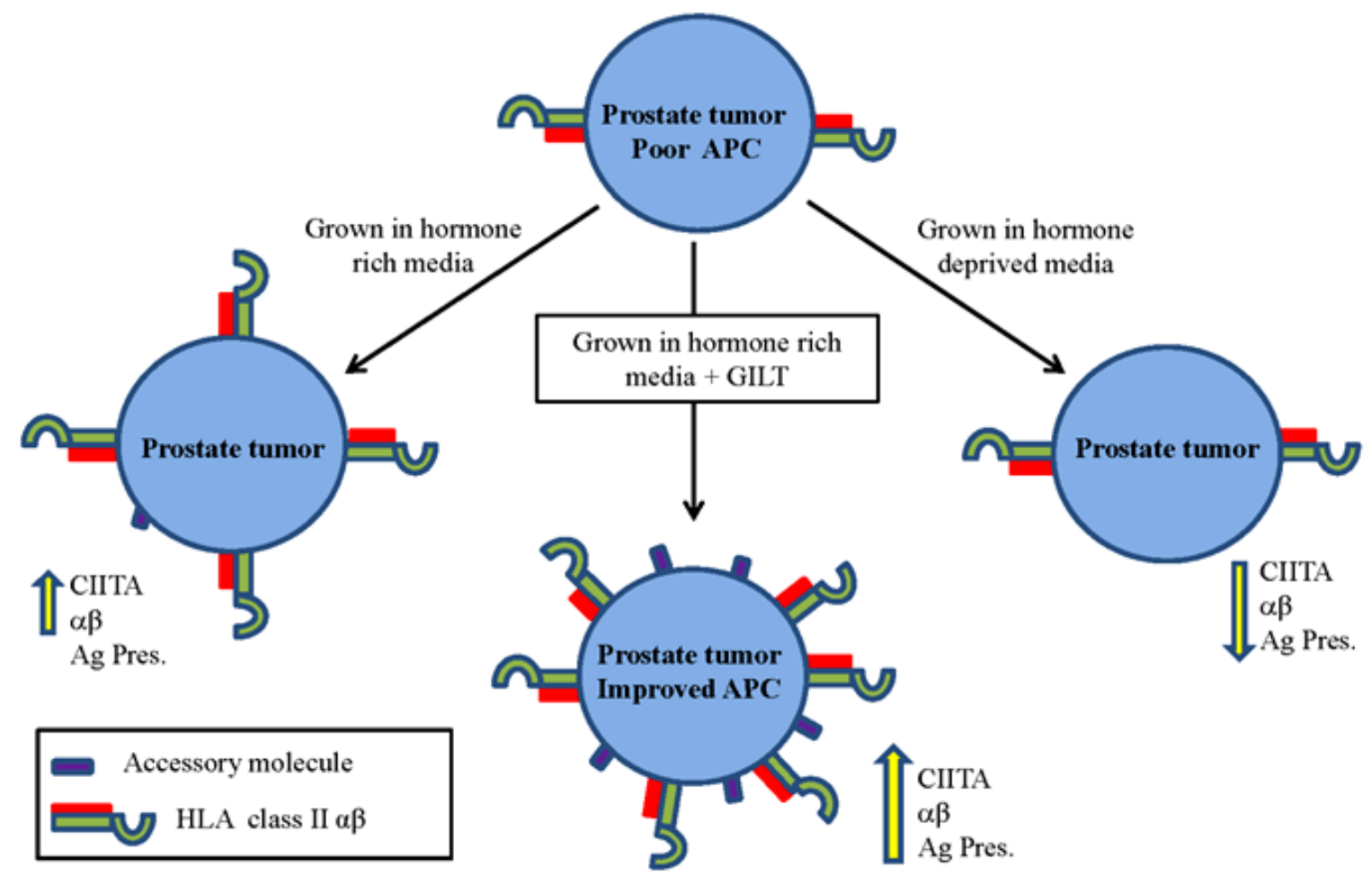

Fig. (2). Growth condition or tumor microenvironment modulates immune components in prostate cancer cells avoiding immune recognition. Prostate cancer cells are poor APCs and express extremely low levels of class II molecules on their surface. When cultured in hormone deprived media (e.g., RPMI+ low hormone serum), no detectable upregulation of class II molecules is seen and Ag presentation capability is unchanged. When the prostate cancer cells are grown in hormone rich media (e.g., RPMI+ high hormone serum), class II expression is upregulated and stable class II $\alpha \beta$ dimers are formed. An increased expression of CIITA is also observed and the Ag presenting capability of the prostate cancer cell is increased. Further improving the Ag processing and presentation of the prostate cancer cells is the induction or introduction of GILT in these cells while cultured in hormone rich media. Together, this supports an increase in adhesion or accessory molecules on prostate cancer cells, inducing enhanced immune recognition of tumor cells.

cines, with a respectable two-thirds showing tumor specific immune responses [8]. Of this population, about half experienced a detectable clinical response to the therapy, further increasing the role for immunotherapy as a future standard of care [8]. Current studies suggest that complete tumor clearance by cancer vaccines alone is unlikely to occur, but that this does not have to happen for some clinical benefit to be gained [7, 8]. Furthermore, reducing the tumor burden and returning a patient back to a state of quiescence between the immune system and the cancer cells could greatly help the prognosis of metastatic cancer patients [8]. A recent case study performed at the Institute of Immunology in Prague highlighted a patient with hormone-refractory metastatic prostate cancer who was successfully treated with combined chemoimmunotherapy [8]. After the patient showed noresponse to current standards of care (irradiation and chemotherapy), the patient was enrolled in a new therapy that involved regular vaccinations with DC loaded with killed LnCap prostate cancer cells combined with palliative chemotherapy with docetaxel in alternating administration [8]. The study showed that noticeable cancer cell-specific immune responses were detectable from the DC-based vaccine therapy and the patient showed marked improvement in the clinical and laboratory setting as measured by the decrease of serum PSA levels by $90 \%$, and at the time of publication, the patient remained in good clinical status [8]. This case study illustrates the benefit of combination chemoimmunotherapy at improving the clinical outcome of patient who had seemingly no viable option to combat the disease. This represents a new mechanism for improvement of current immunotherapy by adding alternating chemotherapy sessions to further reduce tumor burden. Case studies such as this one continue to show the validity of immunotherapy for treatment of prostate cancer. If these means of treatment could be improved to include class II activation through restricted tumor epitopes and improved class II processing by prostate cancer cells through tumor environment modification, then a new gold standard for cancer vaccine treatment could be established.

\section{CONCLUSIONS}

As mentioned in this review, the importance of the HLA class II pathway in developing more effective strategies for cancer vaccines must not be overlooked. Without eliciting a CD4+ $\mathrm{T}$ cell response, immunotherapy will never create a prolonged CTL response or develop long-lasting tumorspecific memory cells $[4,22,42]$. In this review, we also illustrated some of the discoveries made in class II vaccine strategies involving Ii and in class II-restricted prostate cancer Ags [22, 23, 36]. Also mentioned was how prostate cancer cells can be modified to express detectable levels of the class II dimer on their surface needed for CD4+ T cell recognition [4]. This review also highlighted a case study in which combined chemoimmunotherapy using alternating sessions of DC-based prostate cancer vaccinations and pal- 
liative docetaxel therapy resulted in the improved clinical outcome of a patient with hormone-refractory metastatic prostate cancer [8]. These advances in the understanding of prostate cancer class II-processing and presentation will further expand this area of targeting tumors by immune cells. In all, this review provides a framework for the continued improvement of new prostate cancer immune therapy strategies.

\section{ACKNOWLEDGEMENTS}

This work was supported by grants from the Leukemia and Lymphoma Society (\#3024) and National Institutes of Health (CA129560) to A.H.

\section{LIST OF ABBREVIATIONS}

\begin{tabular}{|c|c|c|}
\hline HLA & $=$ & Human Leukocyte Antigen \\
\hline PSA & $=$ & Prostate Specific Antigen \\
\hline PSMA & $=$ & Prostate Specific Membrane Antigen \\
\hline PAP & $=$ & Prostatic Acid Phosphatase \\
\hline GILT & $=$ & $\begin{array}{l}\text { Gamma-Interferon-inducible Lysosomal } \\
\text { Thiol reductase }\end{array}$ \\
\hline TcR & $=$ & T cell Receptor \\
\hline CTL & $=$ & Cytotoxic T Lymphocyte \\
\hline
\end{tabular}

[1] National Cancer Institute. Bethesda, MD: National Cancer Institute 2009; [updated 2009; cited 2009 6.18.09]; Available from: http://www.cancer.gov/cancertopics/types/prostate.

[2] Wilkinson R, Kassianos AJ, Swindle P, Hart DN, Radford KJ. Numerical and functional assessment of blood dendritic cells in prostate cancer patients. Prostate 2006; 66(2): 180-92.

[3] Arlen PM, Dahut WL, Gulley JL. Immunotherapy for prostate cancer: what's the future? Hematol Oncol Clin North Am 2006; 20(4): 965-83, xi.

[4] Younger AR, Amria S, Jeffrey WA, Mahdy AE, Goldstein OG, Norris JS. HLA class II antigen presentation by prostate cancer cells. Prostate Cancer Prostatic Dis 2008; 11(4): 334-41.

[5] Basler M, Groettrup M. Advances in prostate cancer immunotherapies. Drugs Aging 2007; 24(3): 197-221.

[6] Fong L, Small EJ. Immunotherapy for prostate cancer. Curr Urol Rep 2006; 7(3): 239-46.

[7] Vieweg J. Immunotherapy for advanced prostate cancer. Rev Urol 2007; 9 (Suppl 1): S29-38.

[8] Rozkova D, Tiserova H, Fucikova J, Last'ovicka J, Podrazil M, Ulcova H. FOCUS on FOCIS: combined chemo-immunotherapy for the treatment of hormone-refractory metastatic prostate cancer. Clin Immunol 2009; 131(1): 1-10.

[9] McNeel DG. Prostate cancer immunotherapy. Curr Opin Urol 2007; 17(3): 175-81

[10] Karnes RJ, Whelan CM, Kwon ED. Immunotherapy for prostate cancer. Curr Pharm Des 2006; 12(7): 807-17.

[11] Slovin SF. Tribulations or triumphs in prostate cancer immunotherapy: on the road to victory? Expert Rev Anticancer Ther 2008; 8(3): 465-74.

[12] Slovin SF. Pitfalls or promise in prostate cancer immunotherapywhich is winning? Cancer J 2008; 14(1): 26-34.

[13] Amria S, Cameron C, Stuart R, Haque A. Defects in HLA class II antigen presentation in B-cell lymphomas. Leuk Lymphoma 2008; 49(2): 353-5.

[14] Busch R, Rinderknecht CH, Roh S, Lee AW, Harding JJ, Burster T. Achieving stability through editing and chaperoning: regulation of MHC class II peptide binding and expression. Immunol Rev 2005; 207: 242-60.

[15] Blum JS, Cresswell P. Role for intracellular proteases in the processing and transport of class II HLA antigens. Proc Natl Acad Sci USA $1988 ; 85(11)$ : 3975-9.
[16] Ostrand-Rosenberg S. Immune surveillance: a balance between protumor and antitumor immunity. Curr Opin Genet Dev 2008; 18(1): 11-8.

[17] Haque A, Blum JS. New insights in antigen processing and epitope selection: development of novel immunotherapeutic strategies for cancer, autoimmunity and infectious diseases. J Biol Regul Homeost Agents 2005; 19(3-4): 93-104.

[18] Dow C, Oseroff C, Peters B, Nance-Sotelo C, Sidney J, Buchmeier M. Lymphocytic choriomeningitis virus infection yields overlapping CD4+ and CD8+ T-cell responses. J Virol 2008; 82(23): 11734-41.

[19] Amria S, Hajiaghamohseni LM, Harbeson C, Zhao D, Goldstein O, Blum JS. HLA-DM negatively regulates HLA-DR4-restricted collagen pathogenic peptide presentation and $\mathrm{T}$ cell recognition. Eur $\mathrm{J}$ Immunol 2008; 38(7): 1961-70.

[20] Goldstein OG, Hajiaghamohseni LM, Amria S, Sundaram K, Reddy SV, Haque A. Gamma-IFN-inducible-lysosomal thiol reductase modulates acidic proteases and HLA class II antigen processing in melanoma. Cancer Immunol Immunother 2008; 57(10): 1461-70.

[21] Haque A, Das A, Hajiaghamohseni LM, Younger A, Banik NL, Ray SK. Induction of apoptosis and immune response by all-trans retinoic acid plus interferon-gamma in human malignant glioblastoma T98G and U87MG cells. Cancer Immunol Immunother 2007; 56(5): 615-25.

[22] Thompson JA, Srivastava MK, Bosch JJ, Clements VK, Ksander $\mathrm{BR}$, Ostrand-Rosenberg S. The absence of invariant chain in MHC II cancer vaccines enhances the activation of tumor-reactive type 1 CD4+ T lymphocytes. Cancer Immunol Immunother 2008; 57(3): 389-98.

[23] Thompson JA, Dissanayake SK, Ksander BR, Knutson KL, Disis ML, Ostrand-Rosenberg S. Tumor cells transduced with the MHC class II Transactivator and CD80 activate tumor-specific CD4+ T cells whether or not they are silenced for invariant chain. Cancer Res 2006; 66(2): 1147-54

[24] Haque MA, Li P, Jackson SK, Zarour HM, Hawes JW, Phan UT. Absence of gamma-interferon-inducible lysosomal thiol reductase in melanomas disrupts $\mathrm{T}$ cell recognition of select immunodominant epitopes. J Exp Med 2002; 195(10): 1267-77.

[25] Dolan BP, Gibbs KD. Tumor-specific CD4+ T cells are activated by "cross-dressed" dendritic cells presenting peptide-MHC class II complexes acquired from cell-based cancer vaccines. J Immunol 2006; (176): 1447-55.

[26] Lepage S, Lapointe R. Melanosomal targeting sequences from gp100 are essential for MHC class II-restricted endogenous epitope presentation and mobilization to endosomal compartments. Cancer Res 2006; 66(4): 2423-32.

[27] Robbins PF, El-Gamil M, Li YF, Zeng G, Dudley M, Rosenberg SA. Multiple HLA class II-restricted melanocyte differentiation antigens are recognized by tumor-infiltrating lymphocytes from a patient with melanoma. J Immunol 2002; 169(10): 6036-47.

[28] Viehl CT, Frey DM, Phommaly C, Chen T, Fleming TP, Gillanders WE. Generation of mammaglobin-A-specific CD4 T cells and identification of candidate CD4 epitopes for breast cancer vaccine strategies. Breast Cancer Res Treat 2008; 109(2): 305-14.

[29] Shen L, Schroers R, Hammer J, Huang XF, Chen SY. Identification of a MHC class-II restricted epitope in carcinoembryonic antigen Cancer Immunol Immunother 2004; 53(5): 391-403.

[30] Matsuzaki J, Qian F, Luescher I, Lele S, Ritter G, Shrikant PA. Recognition of naturally processed and ovarian cancer reactive CD8+ T cell epitopes within a promiscuous HLA class II T-helper region of NY-ESO-1. Cancer Immunol Immunother 2008; 57(8): $1185-95$

[31] Godefroy E, Scotto L, Souleimanian NE, Ritter G, Old LJ, Jotereau F. Identification of two Melan-A CD4+ T cell epitopes presented by frequently expressed MHC class II alleles. Clin Immunol 2006; 121(1): 54-62.

[32] Celis E. Overlapping human leukocyte antigen class I/II binding peptide vaccine for the treatment of patients with stage IV melanoma: evidence of systemic immune dysfunction. Cancer 2007; 110(1): 203-14.

[33] Kubuschok B, Neumann F, Breit R, Sester M, Schormann C, Wagner C. Naturally occurring T-cell response against mutated p21 ras oncoprotein in pancreatic cancer. Clin Cancer Res 2006; 12(4): 1365-72. 
[34] Corman JM, Sercarz EE, Nanda NK. Recognition of prostatespecific antigenic peptide determinants by human CD4 and CD8 T cells. Clin Exp Immunol 1998; 114(2): 166-72.

[35] Wei C, Willis RA, Tilton BR, Looney RJ, Lord EM, Barth RK. Tissue-specific expression of the human prostate-specific antigen gene in transgenic mice: implications for tolerance and immunotherapy. Proc Natl Acad Sci USA 1997; 94(12): 6369-74.

[36] Bosch JJ, Thompson JA, Srivastava MK, Iheagwara UK, Murray TG, Lotem M. MHC class II-transduced tumor cells originating in the immune-privileged eye prime and boost CD4(+) T lymphocytes that cross-react with primary and metastatic uveal melanoma cells. Cancer Res 2007; 67(9): 4499-506.

[37] Piesche M, Hildebrandt Y, Zettl F, Chapuy B, Schmitz M, Wulf G. Identification of a promiscuous HLA DR-restricted T-cell epitope derived from the inhibitor of apoptosis protein survivin. Hum Immunol 2007; 68(7): 572-6.

[38] Dunn GP, Bruce AT, Ikeda H, Old LJ, Schreiber RD. Cancer immunoediting: from immunosurveillance to tumor escape. Nat Immunol 2002; 3(11): 991-8.

[39] Dixon AM, Stanley BJ, Matthews EE, Dawson JP, Engelman DM. Invariant chain transmembrane domain trimerization: a step in MHC class II assembly. Biochemistry 2006; 45(16): 5228-34.

[40] Bryant PW, Lennon-Dumenil AM, Fiebiger E, LagaudriereGesbert C, Ploegh HL. Proteolysis and antigen presentation by MHC class II molecules. Adv Immunol 2002; 80: 71-114.

[41] Neeley YC, Arredouani MS, Hollenbeck B, Eng MH, Rubin MA, Sanda MG. Partially circumventing peripheral tolerance for oncogene-specific prostate cancer immunotherapy. Prostate 2008; 68(7): 715-27.

[42] Haque MA, Hawes JW, Blum JS. Cysteinylation of MHC class II ligands: peptide endocytosis and reduction within APC influences T cell recognition. J Immunol 2001; 166(7): 4543-51.

[43] Arunachalam B, Phan UT, Geuze HJ, Cresswell P. Enzymatic reduction of disulfide bonds in lysosomes: characterization of a gamma-interferon-inducible lysosomal thiol reductase (GILT). Proc Natl Acad Sci USA 2000; 97(2): 745-50.
[44] Schroers R, Shen L, Rollins L, Xiao Z, Sonderstrup G, Slawin K. Identification of MHC class II-restricted T-cell epitopes in prostatespecific membrane antigen. Clin Cancer Res 2003; 9(9): 3260-71.

[45] Klyushnenkova EN, Kouiavskaia DV, Kodak JA, Vandenbark AA, Alexander RB. Identification of HLA-DRB1*1501-restricted T-cell epitopes from human prostatic acid phosphatase. Prostate 2007; 67(10): 1019-28.

[46] O'Donnell PW, Haque A, Klemsz MJ, Kaplan MH, Blum JS. Cutting edge: induction of the antigen-processing enzyme IFNgamma-inducible lysosomal thiol reductase in melanoma cells Is STAT1-dependent but CIITA-independent. J Immunol 2004; 173(2): 731-5.

[47] Hillman GG, Kallinteris NL, Lu X, Wang Y, Wright JL, Li Y. Turning tumor cells in situ into T-helper cell-stimulating, MHC class II tumor epitope-presenters: immuno-curing and immunoconsolidation. Cancer Treat Rev 2004; 30(3): 281-90.

[48] Gerloni M, Zanetti M. CD4 T cells in tumor immunity. Springer Semin Immunopathol 2005; 27(1): 37-48.

[49] Haque A, Hajiaghamohseni LM, Li P, Toomy K, Blum JS. Invariant chain modulates HLA class II protein recycling and peptide presentation in nonprofessional antigen presenting cells. Cell Immunol 2007; 249(1): 20-9.

[50] Arlen PM, Gulley JL. Therapeutic vaccines for prostate cancer: a review of clinical data. Curr Opin Invest Drugs 2005; 6(6): 592-6.

[51] Mohebtash M, Madan RA, Gulley JL, Arlen PM. Therapeutic prostate cancer vaccines: a review of the latest developments. Curr Opin Invest Drugs 2008; 9(12): 1296-301.

[52] Simons JW, Carducci MA, Mikhak B, Lim M, Biedrzycki B, Borellini F. Phase I/II trial of an allogeneic cellular immunotherapy in hormone-naive prostate cancer. Clin Cancer Res 2006; 12(11 Pt 1): 3394-401.

[53] Lin AM, Hershberg RM, Small EJ. Immunotherapy for prostate cancer using prostatic acid phosphatase loaded antigen presenting cells. Urol Oncol 2006; 24(5): 434-41.

(c) Doonan and Haque; Licensee Bentham Open.

This is an open access article licensed under the terms of the Creative Commons Attribution Non-Commercial License (http://creativecommons.org/licenses/by-nc/3.0/) which permits unrestricted, non-commercial use, distribution and reproduction in any medium, provided the work is properly cited. 